\title{
PROPUESTA DE SISTEMA DE COSTOS E INCIDENCIA EN LA UTILIDAD DE LA LAVANDERÍA INDUSTRIAL WASH S.A.C.
}

\author{
PROPOSAL OF THE COST SYSTEM AND ITS IMPACT ON THE UTILITY OF LAUNDRY \\ INDUSTRIAL WASH S.A.C.
}
José Carlos Humberto Soto Mujica Universidad del Pacífico Lima, Perú

ORCID: https://orcid.org/0000-0002-4747-8840

Correo electrónico: jsotomujica@yahoo.es

\section{RESUMEN}

Objetivo: Determinar la incidencia del sistema de costos en la utilidad de la lavandería Industrial Wash S.A.C., año 2018. Método: La investigación fue cualitativa. La muestra estuvo conformada por tres trabajadores del área contable y el propietario. Las técnicas fueron la entrevista y el análisis documental. Resultados: Se estimaron los costos sobre la base de los datos de la contabilidad financiera, obteniendo como utilidad bruta anual S/ 14308307 , operativa S/ 13422474 y neta S/ 9462844 . Por otro lado, con la estimación de los costos bajo el sistema de costos por órdenes de trabajo, las utilidades fueron S/ 14524 658, S/ 13719370 y S/ 9672 156, respectivamente. Se obtiene que la diferencia de ambos métodos fue positiva a favor del sistema de costos por órdenes de trabajo. Según la mayoría de entrevistados, el método de costeo más apropiado sería el sistema de costeo por órdenes de trabajo. Conclusión: La lavandería Industrial Wash S.A.C. no tiene un sistema de costos bien definido que le brinde información exacta sobre los costos incurridos en el servicio de lavandería, ni sus utilidades; sin embargo, los datos han permitido evaluar un sistema de costos por órdenes de trabajo con un resultado positivo en las utilidades.

Palabras clave: Sistema de costos; utilidad; propuesta; precio de venta; costo del servicio.

\begin{abstract}
Objective: Determine the incidence of the cost system on the utility of the laundry Industrial Wash S.A.C., year 2018. Method: The research was qualitative. The sample was comprised of three workers from the accounting area and the owner. The techniques were the documentary analysis and the interview. Results: The costs were estimated based on the financial accounting data, obtaining an annual gross profit of S/ 14308 307, an operating profit of S/ 13422474 and a net income of S/ 9462 844. On the other hand, the estimate of costs under the work order cost system was S/ 14524658 per year, operating income of S/ 13719370 and net income of S/ 9672 156. It was found that the difference of both methods was positive in favor of the cost system for work orders. According to the majority of those interviewed, the most appropriate costing method would be the work order costing system. Conclusion: Laundry Industrial Wash S.A.C. does not have a well-defined cost system that provides accurate information on the costs incurred in the laundry service, nor its profits; however, the data has allowed to evaluate a cost system for work orders with a positive result in profits.
\end{abstract}

Keywords: Cost system; utility, proposal; sale price; service cost.

(C) Los autores. Este artículo es publicado por la revista Quipukamayoc de la Facultad de Ciencias Contables, Universidad Nacional Mayor de San Marcos. Este es un artículo de acceso abierto, distribuido bajo los términos de la licencia Creative Commons Atribución 4.0 Internacional (CC BY 4.0) [https://creativecommons. org/licenses/ by/4.0/deed.es] que permite el uso, distribución y reproducción en cualquier medio, siempre que la obra original sea debidamente citada de su fuente original. 


\section{INTRODUCCIÓN}

Las empresas cuentan con diversas fuentes de información que les permite conocer su desempeño para tomar decisiones y determinar medidas específicas para alcanzar sus objetivos. Así, el sistema de costos es una herramienta útil que brinda datos precisos sobre los factores claves que intervienen en el proceso de producción, estos datos se ven reflejados en las utilidades de la empresa. Según Moreno, Ruiz y Valenzuela (2018) "el entorno empresarial competitivo hace que los empresarios busquen herramientas que les permita una supervivencia en el mercado, parte de esas herramientas son los sistemas de costos, los cuales facilitan la toma de decisiones" (p. 1).

En ese sentido, el sistema de costos contempla el registro sistemático de las transacciones financieras relacionadas con los factores de producción para determinar el costo, labor exclusiva de los profesionales de la contabilidad. Según la teoría, el sistema de costos:

Constituye un conjunto de procedimientos, técnicas, registros e informes estructurados sobre la base de la teoría de la partida doble y otros principios técnicos, que tienen por objeto la determinación de los costos unitarios de producción y el control de las operaciones de producción. (Chambergo, 2012, p. 2)

Como se puede apreciar, el fin último de un sistema de costos es determinar el costo unitario de un producto o de un servicio, y permitir el control de las operaciones de fabricación del producto o prestación del servicio. En relación con ello, "los sistemas de costeo tradicionales son el sistema por órdenes específicas y el sistema por procesos" (Chambergo, 2012, p. 118), por lo que, la elección de uno u otro sistema dependerá de la modalidad de producción que use la empresa, sea a pedido o producción en serie.

Es importante resaltar que "llevar un control de costos (...) no es exclusivo de las grandes empresas, es aplicable también a los negocios de poca o mediana amplitud" (Goñaz y Zevallos, 2018, p. 3). Asimismo, un sistema de costos se aplica tanto para empresas manufactureras como de servicios. Según menciona Choy (2012), "la determinación de los costos en las empresas de servicios es más compleja y diversa, ya que los procedimientos de cálculo dependen del tipo de actividad, y son diversos los servicios" (como se citó en Umpire, 2017, p. 2). Precisamente, las empresas de servicios, por sus características propias, necesitan contar con un sistema de costeo porque:

Un servicio se caracteriza por su naturaleza intangible, no es separable del cliente y no puede ser inventariado (...). Los administradores deben ser capaces de dar un seguimiento a los costos de la prestación de servicios de una manera tan precisa como con los costos de los artículos fabricados. (Hansen, 2010, p. 181)

La determinación de costos en cada operación de la empresa es imperativa al momento de tomar una decisión adecuada, en especial al momento de establecer los precios. Este procedimiento colaborará con el objetivo de elevar las utilidades, ya que se podrá identificar aquellos procesos en los cuales se produce una mayor utilidad. Sin embargo, la formulación de un sistema de costos no es una práctica frecuente en todas las compañías, ya que existen firmas que simplemente funcionan sin esta herramienta o con una poco adecuada a sus necesidades.

Para determinar qué sistema de costos es el apropiado para una empresa, se debe considerar su naturaleza, así como los servicios que brinda, con el objetivo de obtener información precisa. En ese sentido, de acuerdo con Udolkin (2014):

Si la producción o servicio brindado están relacionados con las especificaciones propias de cada cliente y son diferentes entre pedidos, el sistema más adecuado para costear los productos o servicios es el sistema de costeo por órdenes de trabajo (...) si la producción es muy estandarizada, masiva y continua, el sistema de costeo por procesos sería el más adecuado. Igualmente, si un servicio es muy estandarizado, y no requiere un seguimiento de los costos por clientes, el sistema de costeo por procesos sería más recomendable. (p. 117)

Implementar un sistema de costeo por órdenes de trabajo ayuda a la rentabilidad de la empresa, pues a opinión de Barfield (2005) "el costeo por órdenes de trabajo puede ayudar a determinar qué trabajos son verdaderamente rentables y permitir a los administradores a controlar mejor sus costos (...) haciendo que la utilidad aumente" (p. 191).

Un sistema de costeo por órdenes de trabajo no es exclusivo para las empresas manufactureras, también se aplica muy bien para las empresas de servicios, puesto que, tal como afirma Blocher (2008) "el costeo por órdenes de producción se usa mucho en las industrias de servicios (...)" (p. 97) porque cada servicio que se ofrece tiene un costo diferente, dependiendo de las actividades que implica y de las especificaciones de cada cliente, por ello, se debe identificar y agrupar los costos incurridos en cada orden de trabajo.

De lo visto hasta el momento, se puede inferir que tener un sistema de costos es fundamental para una empresa, pues como afirma Horngren (2012) "los sistemas de costeo tienen como finalidad reportar cifras de costos que 
reflejen la manera en que los productos o servicios usan los recursos de una organización” (p. 125).

En este sentido, surgen estudios como el de Arellano (2018), quien realizó una investigación en una empresa industrial, en la cual concluyó que la empresa no cuenta con un sistema de costos que repercute en el precio final deficiente de los productos terminados. Asimismo, Udolkin (2014) señala que para determinar el precio de los productos o servicios y tomar decisiones, las empresas requieren conocer sus costos.

Considerando lo descrito y comparándolo con la situación de la lavandería Industrial Wash S.A.C. (La Victoria, Lima), se formuló la siguiente interrogante: ¿Cómo el sistema de costos incide en la utilidad de la lavandería Industrial Wash S.A.C.?, de la cual se deriva la hipótesis: un sistema de costos incide de manera positiva en la utilidad de la lavandería Industrial Wash S.A.C.

Este estudio se justifica de manera teórica por el marco conceptual sobre el sistema de costos, explicado en la introducción; asimismo, se justifica de manera práctica porque brindará información amplia y actualizada sobre ambas variables (sistema de costos y utilidad). A esto se suma que la presente investigación responde a la obligación e importancia de formular un sistema de costos que se adecúe a la empresa y analizar cómo este incide en su utilidad.

\section{MATERIAL Y MÉTODOS}

La investigación fue de tipo cualitativa. Los entrevistados elegidos fueron tres trabajadores del área contable y el propietario. Las técnicas empleadas fueron el análisis documental y la entrevista, la cual estuvo estructurada por seis preguntas abiertas, diseñadas en función de los objetivos de estudio y dirigida a las cuatro personas de la lavandería.

Se recolectó datos de fuentes secundarias como información contable-administrativa de la empresa Industrial Wash S.A.C. (registros que indicaron a detalle los costos de los materiales requeridos en el proceso de lavado), el salario de la mano de obra empleada en dicho proceso, del personal administrativo y otros; adicionalmente, adicionalmente, se consideraron los costos relacionados con el servicio de lavandería.

Para determinar cómo el sistema de costos incide en la utilidad de la lavandería, se realizó el análisis descriptivo de los costos, para ello, se simularon 15 órdenes de pedido para calcular los costos de los insumos, la mano de obra y los costos indirectos de fabricación. Una vez calculados los costos totales, se conoció el costo unitario de fabricación de dicha orden solicitada y junto con el precio del servicio se pudo calcular la utilidad bruta; por último, se acompañó con la propuesta del sistema de costos.

Con el fin de examinar las entrevistas, se empleó la técnica de análisis de la información, que consistió en identificar las ideas principales para que sean categorizadas y codificadas. En el caso de las categorías, se tomó como referencia las variables de investigación (sistemas de costos y utilidad), y para describir los códigos se tomó como referencia las preguntas realizadas. Luego de identificar las categorías y los códigos, se elaboró la matriz de relaciones, donde se evidencia la información que se encuentra clasificada según los criterios establecidos para su interpretación correspondiente (Ver Tabla 1).

Tabla 1

Identificación de categorías y códigos

\begin{tabular}{|c|c|c|}
\hline Categorías & Códigos & Conclusión \\
\hline \multirow{5}{*}{$\begin{array}{l}\text { Sistema de } \\
\text { costos }\end{array}$} & Forma de trabajo & $\begin{array}{l}\text { No se tiene definido un sistema o método de costeo. Se considera utilizar un } \\
\text { sistema de costeo por proceso, ya que el servicio es continuo y estandarizado } \\
\text { y pasa por diferentes departamentos. El método más apropiado sería el costeo } \\
\text { por órdenes de trabajo. }\end{array}$ \\
\hline & Política interna de costos & $\begin{array}{l}\text { No es completa. Tiene algunas políticas internas, como el control de la materia } \\
\text { prima. }\end{array}$ \\
\hline & Costos de producción / Costos indirectos & $\begin{array}{l}\text { La empresa no realiza una contabilidad de costos (directos e indirectos). No } \\
\text { define costo de producción, los costos son calculados sobre la base de la } \\
\text { competencia. }\end{array}$ \\
\hline & Precio de venta / Costos de producción & $\begin{array}{l}\text { La empresa establece los precios de venta en función de las empresas com- } \\
\text { petidoras. }\end{array}$ \\
\hline & Precio de venta / Precio de la competencia & $\begin{array}{l}\text { La empresa establece el precio sobre la base de lo que cobran las otras em- } \\
\text { presas. }\end{array}$ \\
\hline Utilidad & Margen utilidad bruta & No se tiene un costo establecido por kilo y esto impide calcular la utilidad bruta fija. \\
\hline
\end{tabular}

Fuente: Elaboración propia 


\section{RESULTADOS}

Los resultados de la investigación están estructurados en tres partes. En la primera parte, se muestran los resultados del análisis documental; la segunda parte presenta la descripción de los resultados cualitativos en función del análisis de las entrevistas; y la tercera parte presenta la propuesta de sistema de costos.

\section{Análisis documental}

Se hizo una aproximación de los ingresos, tomando como supuesto un precio de venta de S/ 4,00 por kilo de ropa, según la contabilidad financiera actual y una estimación de los costos. Por un lado, se empleó el costo unitario obtenido de los datos históricos de la contabilidad financiera de la empresa y, por otro lado, el costo unitario basado en el sistema de costos por órdenes de trabajo, obteniendo para ambos casos la utilidad bruta, operativa y neta.

En la Tabla 2, se muestra las utilidades obtenidas en diversos periodos de tiempo, calculadas sobre la base de los datos obtenidos de la contabilidad financiera de la empresa, con un valor de venta de S/ 4,00 por kilo de ropa lavada, el costo de ventas, así como el gasto de despacho y el gasto operativo incurridos por cada kilo de ropa.

En la Tabla 3, se muestra las utilidades obtenidas en diversos periodos de tiempo, aplicando el sistema de órdenes de trabajo para calcular el costo de ventas por kilo de ropa, así como el gasto de despacho y el gasto operativo incurridos por dicho peso.

La Tabla 4 muestra la comparación de las utilidades señaladas en las dos tablas anteriores (2 y 3 ). Se observa que la estimación de los costos obtenidos aplicando el sistema de costos por órdenes de trabajo son menores que los obtenidos de la contabilidad financiera, lo que trae como consecuencia que las distintas utilidades sean mayores. Por lo tanto, se puede apreciar que la incidencia del sistema de costos por órdenes de trabajo sobre la utilidad de la lavandería Industrial Wash S.A.C es positiva.

Tabla 2

Estado de resultados bajo la contabilidad financiera (Expresado en soles)

\begin{tabular}{cccc}
\hline Estado de resultados & Diario & Mensual & Anual \\
\hline Ventas netas & 50400 & 1512000 & 18144000 \\
Costo de ventas & 10655 & 319641 & 3835693 \\
Utilidad bruta & $\mathbf{3 9 7 4 5}$ & $\mathbf{1 1 9 2 3 5 9}$ & $\mathbf{1 4 3 0 8 3 0 7}$ \\
Gastos de despacho & 1202 & 36068 & 432816 \\
Gastos operativos & 1258 & 37751 & 453017 \\
Utilidad operativa & $\mathbf{3 7 2 8 5}$ & $\mathbf{1 1 1 8 5 4 0}$ & $\mathbf{1 3 4 2 2} \mathbf{4 7 4}$ \\
Impuesto a la renta (29,5\%) & 10999 & 329969 & $\mathbf{3 9 5 9 6 3 0}$ \\
Utilidad neta & $\mathbf{2 6 ~ 2 8 6}$ & $\mathbf{7 8 8 5 7 0}$ & $\mathbf{9 4 6 2 8 4 4}$ \\
\hline
\end{tabular}

Fuente: Elaboración propia

Tabla 3

Estado de resultados bajo el sistema de costos por órdenes de trabajo (Expresado en soles)

\begin{tabular}{|c|c|c|c|}
\hline Estado de resultados & Diario & Mensual & Anual \\
\hline Ventas netas & 50400 & 1512000 & 18144000 \\
\hline Costo de ventas & 10054 & 301612 & 3619342 \\
\hline Utilidad bruta & 40346 & 1210388 & 14524658 \\
\hline Gastos de despacho & 1093 & 32789 & 393462 \\
\hline Gastos operativos & 1144 & 34319 & 411826 \\
\hline Utilidad operativa & 38109 & 1143281 & 13719370 \\
\hline Impuesto a la renta $(29,5 \%)$ & 11242 & 337268 & 4047214 \\
\hline Utilidad neta & 26867 & 806013 & 9672156 \\
\hline
\end{tabular}

Fuente: Elaboración propia 
Tabla 4

Comparación de estados de resultados (Expresado en soles)

\begin{tabular}{|c|c|c|c|c|c|c|c|c|c|}
\hline \multirow[t]{2}{*}{$\begin{array}{c}\text { Estados de resultados } \\
\text { (EERR) }\end{array}$} & \multicolumn{3}{|c|}{ EERR (Contabilidad Financiera) } & \multicolumn{3}{|c|}{ EERR (Órdenes de trabajo) } & \multicolumn{3}{|c|}{ Diferencia } \\
\hline & Diario & Mensual & Anual & Diario & Mensual & Anual & Diario & Mensual & Anual \\
\hline Ventas netas & 50400 & 1512000 & 18144000 & 50400 & 1512000 & 18144000 & & & \\
\hline Costo de ventas & 10655 & 319641 & 3835693 & 10054 & 301612 & 3619342 & & & \\
\hline Utilidad bruta & 39745 & 1192359 & 14308307 & 40346 & 1210388 & 14524658 & -601 & -18029 & -216350 \\
\hline Gastos de despacho & 1202 & 36068 & 432816 & 1093 & 32789 & 393462 & & & \\
\hline Gastos operativos & 1258 & 37751 & 453017 & 1144 & 34319 & 411826 & & & \\
\hline Utilidad operativa & 37285 & 1118540 & 13422474 & 38109 & 1143281 & 13719370 & -825 & -24741 & -296896 \\
\hline Impuesto a la renta $(29,5 \%)$ & 10999 & 329969 & 3959630 & 11242 & 337268 & 4047214 & & & \\
\hline Utilidad neta & 26286 & 788570 & 9462844 & 26867 & 806013 & 9672156 & -581 & -17443 & -209312 \\
\hline
\end{tabular}

Fuente: Elaboración propia

\section{Análisis de la entrevista}

En cuanto a la forma de trabajo (pregunta 1), un $75 \%$ señala que es por pedido de clientes, y el $25 \%$ afirma que es proceso continuo. Respecto a la política interna de costos (pregunta 2), el 100\% considera que sí existe, pero de manera parcial. Sobre el uso de la contabilidad de costos (pregunta 3), el 100\% afirma que la empresa no cuenta con ello. En relación con el precio de venta (pregunta 4), el $100 \%$ señala que se fija sobre la base del precio de otras lavanderías. Respecto a la competencia (pregunta 5), el $100 \%$ considera que no hay diferencia, pues el precio de venta es el mismo. Sobre el margen de utilidad bruta (pregunta 6), el 100\% afirma que no se puede saber al no tener el costo de producción (Ver Tabla 1).

Los resultados de la entrevista confirman que la empresa no tiene implementado un sistema de costos ni de contabilidad de costos; por lo tanto, no aprovecha esta herramienta útil para obtener información que le permita calcular su costo de producción, el precio de venta y la utilidad. Asimismo, se afirma que la empresa establece su precio de venta sobre la base del precio de la competencia y no por sí misma, y además que la empresa desconoce el margen de utilidad bruta al no contar con información del costo de producción.

Tres de los cuatro entrevistados afirman que el sistema más adecuado sería el costeo por órdenes de trabajo, puesto que la lavandería Industrial Wash S.A.C. realiza sus servicios por pedido o por lotes de ropa de cada cliente. Precisamente, esta investigación contribuye a que la empresa pueda implementar un sistema de costos que le permita solucionar la falta de información interna y establecer una mejor gestión de sus operaciones y adecuada toma de decisiones.
Propuesta del sistema de costos para Industrial Wash S.A.C.

De conformidad con el objetivo propuesto de estimar los costos de los servicios brindados por la empresa de lavandería Industrial Wash S.A.C., el sistema de costos propuesto toma como fundamento a la teoría de costos por órdenes específicas (o de trabajo), debido a que es la que más se ajusta a los costos generados en la empresa a estudiar. Se llegó a esta conclusión luego de observar los resultados de la entrevista.

A continuación, se decribirá los documentos necesarios que debe implementar la lavandería Industrial Wash S.A.C. relacionados con la gestión y el control de los elementos de costo del servicio que brinda.

\section{Requerimiento de material}

El responsable del manejo de los materiales es usualmente el departamento o área de compras. Es importante que exista una inspección de entradas y salidas de materia prima, el cual puede ser a través de un instrumento del tipo Kardex. En la Figura 1, se presenta el modelo de Kardex usado por la lavandería Industrial Wash S.A.C. para llevar el control del movimiento de los insumos, en el cual se considera la fecha, descripción, cantidad, costo unitario y costo total.

\section{Nota de despacho}

El responsable de la recepción de los materiales verifica y concilia con la orden de compra y la factura. Si existiera algún error, se debe emitir una nota de despacho cada vez que algún material ingresa al área de producción para iniciar el proceso productivo. La Figura 2 presenta el modelo de la nota de despacho que empleará la lavandería Industrial 
Wash S.A.C. con la información completa que facilita la corrección de los errores cometidos.

\section{Nota de Devolución}

El presente documento será emitido siempre y cuando haya una devolución de los materiales entregados al área de producción; servirá para tener control de las demoras que pudieran generarse en cada una de las operaciones. La Figura 3 presenta la nota de devolución que será empleada para realizar las devoluciones al área de producción.

\section{Tarjetas de tiempo}

Las tarjetas de tiempo permitirán realizar el seguimiento del personal que ha intervenido en las diferentes órdenes de trabajo de la empresa, con las cuales se tendrá mayor detalle en lo referente a las órdenes de trabajo. Asimismo, consignarán las paradas de máquinas, contingencias o algún otro evento inusual que haya generado la demora en la finalización de alguna orden de trabajo. Con ello se tendrá una mejor estimación de los tiempos que demoran en atenderse las órdenes de trabajo, de modo que, la supervisión tenga una referencia para que, posteriormente, determinen las órdenes de mayor costo al esperado, según los tiempos totales que haya empleado cada orden. En la Figura 4, se presenta la tarjeta de tiempo a emplear para realizar un adecuado control de las órdenes de trabajo.

\section{Orden de Trabajo}

Este documento permite que todo el equipo tenga una idea sobre el inicio de la orden de trabajo; contiene la suficiente

\begin{tabular}{|c|c|c|c|c|c|c|c|c|c|c|}
\hline \multicolumn{11}{|c|}{$\begin{array}{l}\text { INDUSTRIAL WASH } \\
\text { KARDEX }\end{array}$} \\
\hline \multicolumn{2}{|c|}{ PEDIDO } & 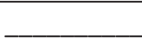 & \multicolumn{2}{|c|}{ MÉTODO } & 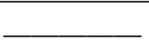 & \multicolumn{2}{|c|}{ EXISTENCIA MÁXIMA } & & & \\
\hline \multicolumn{2}{|c|}{ CANTIDAD } & & \multicolumn{2}{|c|}{ MEDIDA } & & & & & & \\
\hline \multicolumn{2}{|c|}{ FECHA DE INICIO } & & \multicolumn{2}{|c|}{ FECHA DE TÉRMINO } & & \multicolumn{2}{|c|}{ EXISTENCIA MÍNIMA } & & & \\
\hline \multirow[b]{2}{*}{ FECHA } & \multirow[b]{2}{*}{ DESCRIPCIÓN } & \multicolumn{3}{|c|}{ ENTRADAS } & \multicolumn{3}{|c|}{ SALIDAS } & \multicolumn{3}{|c|}{ EXISTENCIAS } \\
\hline & & CANTIDAD & $\begin{array}{l}\text { COSTO } \\
\text { UNITARIO }\end{array}$ & $\begin{array}{l}\text { COSTO } \\
\text { TOTAL }\end{array}$ & CANTIDAD & $\begin{array}{c}\text { COSTO } \\
\text { UNITARIO }\end{array}$ & $\begin{array}{l}\text { COSTO } \\
\text { TOTAL }\end{array}$ & CANTIDAD & $\begin{array}{l}\text { COSTO } \\
\text { UNITARIO }\end{array}$ & $\begin{array}{l}\text { COSTO } \\
\text { TOTAL }\end{array}$ \\
\hline & & & & & & & & & & \\
\hline & & & & & & & & & & \\
\hline & & & & & & & & & & \\
\hline
\end{tabular}

Figura 1. Kardex de la lavandería Industrial Wash S.A.C.

Fuente: Elaboración propia

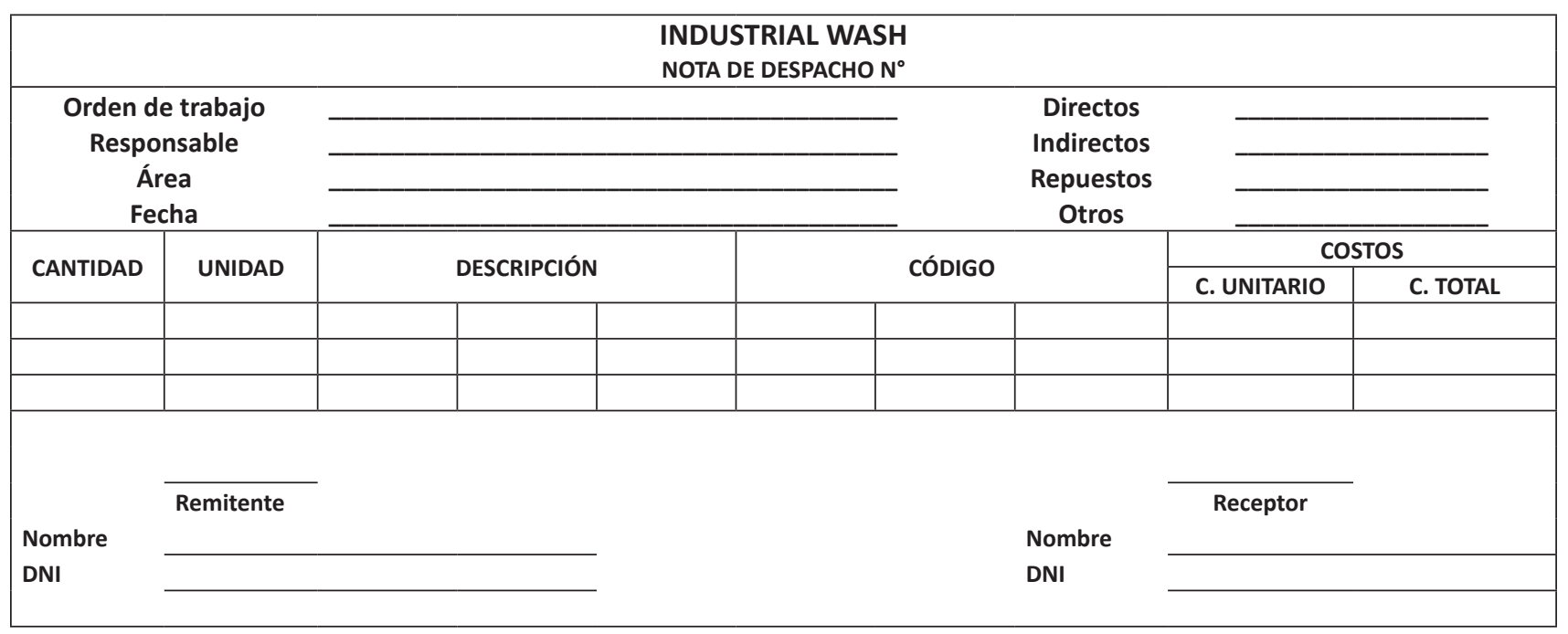

Figura 2. Nota de despacho de lavandería Industrial Wash S.A.C.

Fuente: Elaboración propia 


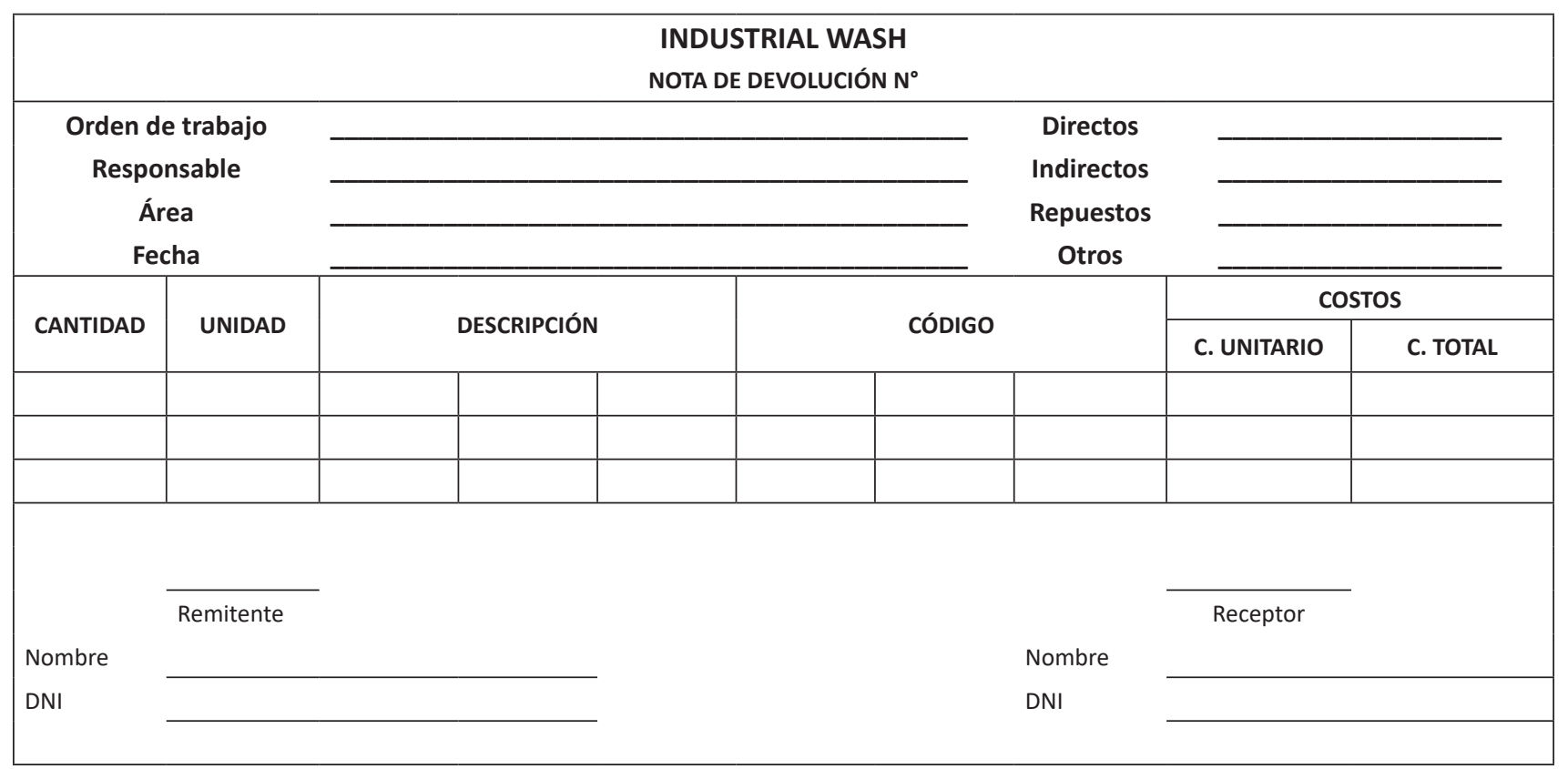

Figura 3. Nota de devolución de lavandería Industrial Wash S.A.C.

Fuente: Elaboración propia

\begin{tabular}{|c|c|c|c|c|c|}
\hline \multicolumn{6}{|c|}{$\begin{array}{l}\text { INDUSTRIAL WASH } \\
\text { TARJETA DE TIEMPO }\end{array}$} \\
\hline \multirow{2}{*}{\multicolumn{2}{|c|}{$\begin{array}{l}\text { Nombre } \\
\text { Fecha de inicio del trabajo }\end{array}$}} & & \multirow{2}{*}{$\begin{array}{l}\text { Orden de Trabajo } \mathrm{N}^{\circ} \\
\text { Unidades Terminadas }\end{array}$} & & \\
\hline & & & & & \\
\hline HORA DE INICIO & HORA DE TÉRMINO & HORAS PRODUCIDAS & PARO DE MÁQUINAS & $\begin{array}{c}\text { CONTRA } \\
\text { TIEMPOS }\end{array}$ & OTROS \\
\hline & & & & & \\
\hline & & & & & \\
\hline & & & & & \\
\hline & & Jefe de & & & \\
\hline
\end{tabular}

Figura 4. Tarjeta de tiempo de lavandería Industrial Wash S.A.C.

Fuente: Elaboración propia

información para la adecuada ejecución de los procesos, la cual permitirá obtener un producto final satisfactorio. En la Figura 5, se presenta la orden de trabajo que contiene información detallada.

\section{Hoja de Costos}

Este documento lleva un registro individual de todos los costos de producción incurridos en cada orden de trabajo. Con dicho documento, el Departamento de Contabilidad tendrá información para el manejo adecuado de las finanzas de la empresa, pues se sabrá los rubros de mayor costo $y$, a su vez, se podrá brindar mejores sugerencias relacionadas con los costos que puedan reducirse en un futuro. Por ello, para una minimización de errores al momento de realizar el análisis, se requiere que la hoja de costos se encuentre actualizada. En la Figura 6, se muestra el registro que permite llevar una contabilidad eficiente de los costos necesarios para brindar los servicios, así como, calcular el precio de venta. 


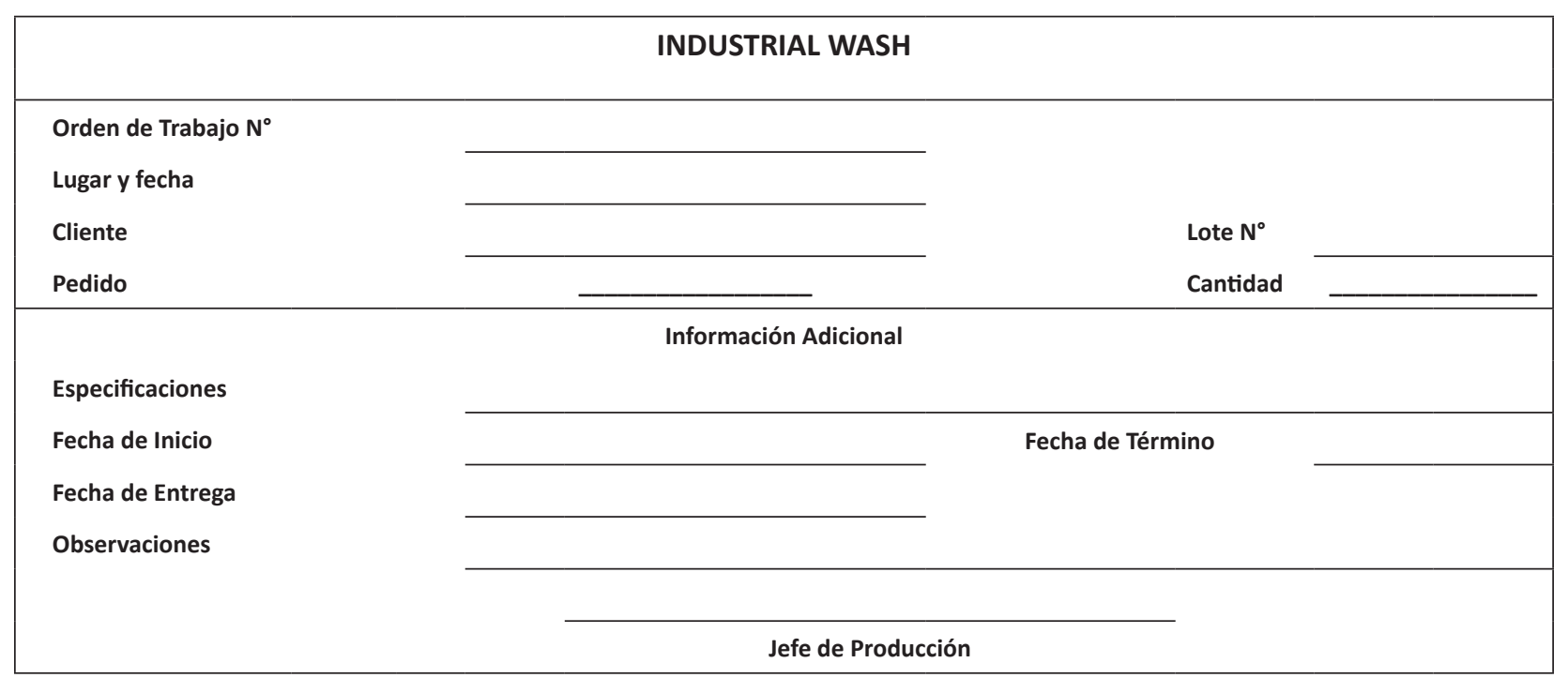

Figura 5. Orden de trabajo de lavandería Industrial Wash S.A.C.

Fuente: Elaboración propia

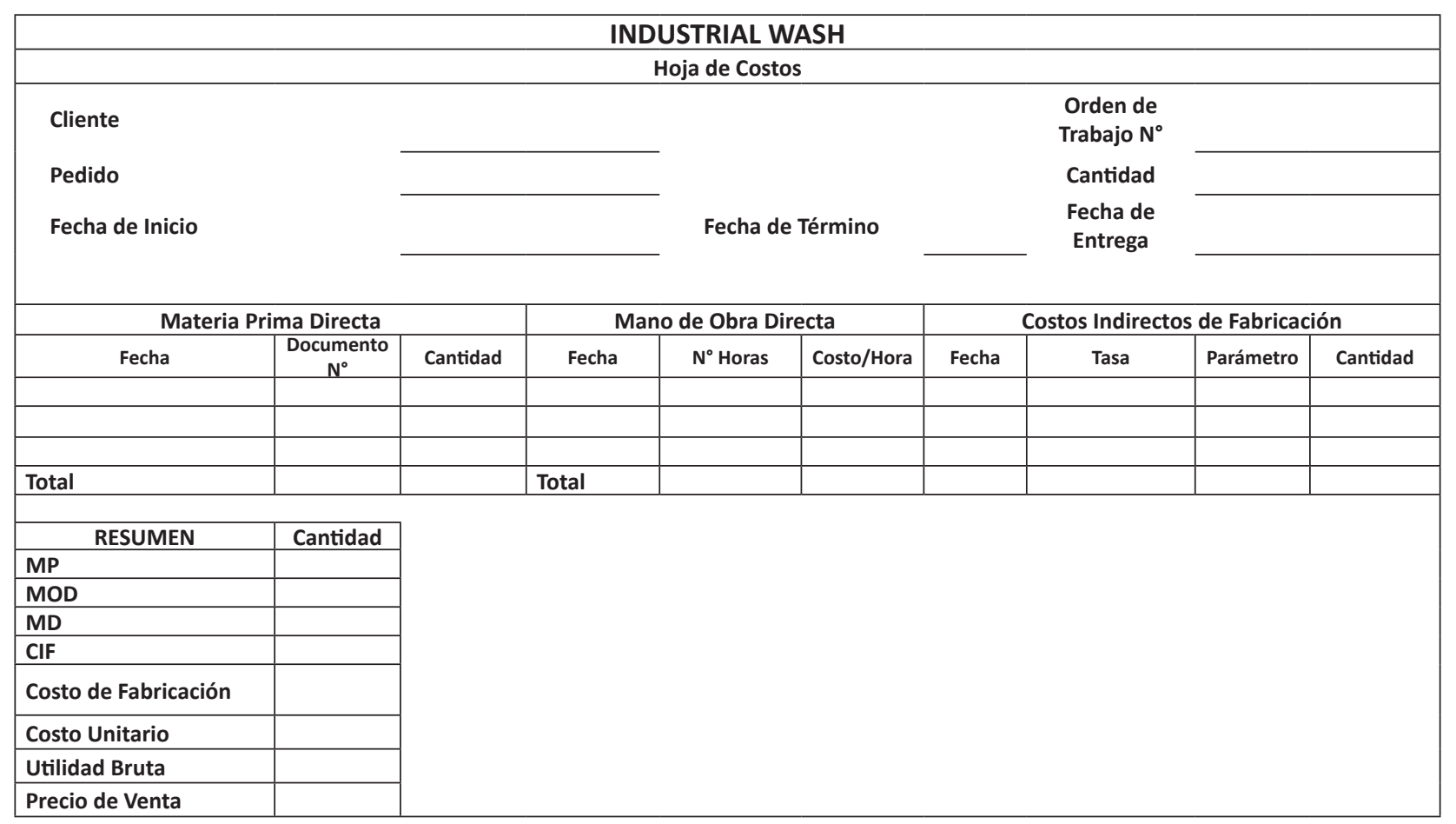

Figura 6. Hoja de costos de lavandería Industrial Wash S.A.C.

Fuente: Elaboración propia

\section{DISCUSIÓN}

El personal del área responsable y el propietario de la lavandería corroboraron que la empresa no tiene una forma de trabajo para establecer los costos. Sin embargo, como se indicó en los resultados de las entrevistas, tres de los cuatro encuestados señalaron que, según el flujo operativo que realizan, le correspondería un sistema de costeo por órdenes de trabajo, ya que la atención que brindan es por lotes de ropa de cada cliente. 
Al no tener un sistema de costeo, no se puede establecer ningún costo de producción, en consecuencia, no se puede estimar la utilidad y rentabilidad obtenida. Esta situación también fue observada por López (2018), quien efectuó su investigación en una empresa electromecánica y determinó que "la empresa no cuenta con un sistema de costeo (...) estas falencias impactan sobre la rentabilidad de la empresa" (p. 62).

Sumado a ello, algunas empresas no determinan los costos reales de producción, así lo señalaron Fernández y Rubio (2019) en su investigación realizada en una empresa que se dedica a la producción de vinos, en la cual concluyeron que "se diseñó un sistema de costos por órdenes específicas por cuanto la gerencia no establece de manera real cada uno de los costos (...) dificultándole de este modo conocer el precio real de los productos" (p. 57).

Del análisis documental, con los datos que contaba la empresa, se realizó una comparación de costos y una estimación, a partir de las cuales se identificó que los costos agrupados por pedidos son menores. Luego, se realizó un seguimiento a las órdenes de trabajo simuladas, y se obtuvo un incremento anual de las utilidades. Se concluyó que la incidencia del sistema de costeo por órdenes de trabajo sobre la utilidad de la lavandería Industrial Wash S.A.C es positiva; resultado similar al encontrado por Umpire (2017), quien determinó la influencia de los costos por órdenes de trabajo en la rentabilidad de un estudio contable y concluyó que "una empresa de servicios lleva un registro adecuado y control eficiente de cada elemento del costo mediante órdenes de trabajo" (p. 148), asimismo, estableció “cómo se relacionan las órdenes de trabajos finales con la rentabilidad financiera” (p. 148).

En la literatura consultada, se encontraron resultados favorables para la implementación de sistemas de costos por órdenes de trabajo, como el referido por Pinedo (2018), quien estableció que "un sistema de costos por órdenes de producción permitirá conocer los costos reales de los productos que elabora" (p. 61). Asimismo, Blandón, Cano y Cruz (2021) concluyeron que "la adecuada implementación de un sistema de costos por órdenes específicas proporciona herramientas necesarias para llevar un mejor control en el área administrativa y contable" (p. 85). De igual manera, Guillen e Infanzón (2019) demostraron que "el costeo por órdenes brinda a detalle los costos indirectos que se utilizaron en cada orden de trabajo a diferencia de otro sistema convencional. Por ello, la rentabilidad es más realista” (p. 189).

En conclusión, la investigación presenta que la lavandería Industrial Wash S.A.C. no tiene implementado un sistema de costos que permita conocer el costo del servicio de producción de lavandería o sus utilidades; además que establece su precio de venta sobre la base de la competencia, y desconoce el margen de utilidad bruta al no contar con información del costo del servicio de producción de lavandería. Se ha demostrado que el sistema de costos más adecuado para la empresa sería el costeo por órdenes de trabajo, pues la lavandería realiza sus servicios por pedido o lotes de ropa de cada cliente; también quedó demostrado la incidencia económica favorable en las distintas utilidades de la empresa al aplicar un sistema de costos por órdenes de trabajo, comparando los resultados obtenidos y los resultados de la contabilidad financiera. Por lo tanto, se recomienda implementar en la lavandería Industrial Wash S.A.C. el sistema de costos por órdenes de trabajo que le permitirá a la gerencia conocer el costo real de producción del servicio de lavandería para así determinar el precio de venta y la utilidad generada.

Finalmente, la agenda para futuras investigaciones debería tratar de responder las siguientes interrogantes: ¿Cuál sería la repercusión de implementar un sistema de costeo por procesos? y ¿sería factible implementar el sistema de costeo por actividades (costeo ABC) en empresas de servicios industriales?

\section{REFERENCIAS}

Arellano, L. (2018). Implementación de costos ABC y su incidencia en la rentabilidad en una empresa Industrial, Lima, 2018 (Tesis para optar el título profesional de Contabilidad y Auditoría). Recuperada de http://repositorio.uwiener.edu.pe/handle/123456789/2064

Barfield, J. (2005). Contabilidad de costos. Tradiciones e innovaciones (5. $\left.{ }^{\mathrm{a}} \mathrm{ed}.\right)$. México D.F.: Thomson Editores.

Blandón, M., Cano, R., \& Cruz, Y. (2021). Implementación de un sistema de costos por órdenes específicas $y$ su incidencia en los resultados financieros en la fábrica de cajas Rey Martínez en la ciudad de Estelí durante el mes de julio del año 2020. (Tesis para optar el título en Contaduría Pública y Finanzas, Universidad Nacional Autónoma de Nicaragua, Nicaragua). Recuperada de http://repositorio.unan.edu.ni/id/eprint/15900

Blocher, E. (2008). Administración de costos. Un enfoque estratégico (4. ${ }^{\mathrm{a}}$ ed.). México D.F: McGraw-Hill.

Chambergo, I. (2012). Sistemas de costos, diseño e implementación en las empresas de servicios, comerciales e industriales. Lima: Instituto Pacífico S.A.

Fernández, M., \& Rubio, D. (2019). Diseño de un sistema de costos por órdenes específicas en la producción de vino para sincerar la rentabilidad en Narváez SAC, Juanjuí 2019 (Tesis para obtener el título profesional 
de contador público). Recuperada de https://hdl.handle.net/20.500.12692/43613

Goñaz, E., \& Zevallos, W. (2018). Determinación de un sistema de costos por procesos para mejorar la rentabilidad en la empresa Panadería Oriental S.R.L. de la ciudad de Iquitos, 2016 (Tesis para obtener el título profesional de contador público). Recuperada de http://repositorio.ucp.edu.pe/handle/UCP/470

Guillen, C., \& Infanzón, L. (2019). El sistema de costeo por órdenes y su impacto en la situación financiera en las empresas de servicios de arquitectura de Lima, año 2018 (Tesis para obtener el título profesional de licenciado en Contabilidad). Recuperada de http://hdl.handle. net/10757/625862

Hansen, D. (2010). Administración de costos. Contabilidad $y$ control (5. ${ }^{a}$ ed.). México D.F.: CENGAGE Learning.

Horngren, C. (2012). Contabilidad de costos. Un enfoque gerencial (14. ${ }^{a}$ ed.). México D.F.: Pearson Educación de México.

López, G. (2018). Método de costeo por órdenes de pedido. Electromecánica Estévez, año 2018 (Tesis para optar el título de contador público, Universidad Siglo 21, Argentina). Recuperada de https://repositorio.uesiglo21. edu.ar/handle/ues21/17421
Moreno, M., Ruiz, R., \& Valenzuela, R. (2018). Diagnóstico del sistema de costos en la microempresa: Cinco casos de estudio. Revista de Investigación Académica Sin Frontera: División de Ciencias Económicas y Sociales, 27(11), 1-26. Recuperado de https://revistainvestigacionacademicasinfrontera.unison.mx/index.php/ $\underline{\text { RDIASF/article/view/168 }}$

Pinedo, E. (2018). Propuesta de un sistema de costos por órdenes de producción en el negocio bienes y servicios E\&M, Lurigancho-Lima, 2018 (Tesis para optar el título de contador público). Recuperada de http://hdl. handle.net/20.500.12840/1346

Udolkin, S. (2014). Contabilidad de costos y de gestión. Lima: Universidad del Pacífico.

Umpire, G. (2017). Sistema de costos por órdenes de trabajo y su influencia en la rentabilidad del estudio contable jurídico BR Perú Mundo Consultores, año 2016 (Tesis para optar el título de contador público). Recuperada de http://repositorio.autonoma.edu.pe/handle/AUTONOMA/426 